\title{
Effect of Machining Parameters in Milling Aluminum Alloy 7075-T6 under MQL Condition
}

\author{
M.Z.A. Yazid, Azreen Zainol, A.M. Mustapaha
}

\begin{abstract}
Minimum quantity lubrication (MQL) is an eco-friendly method, where a small amount of fluid was sprayed to cutting edge in mist form with the aid of the air. The foregoing studies revealed that inappropriate machining parameters without the assistance of the cutting fluid methods became a major challenge in milling aluminum alloy 7075-T6. The paper presents the findings of the experimental work to assess the effect of machining parameters towards cutting tool life and machined surface roughness in milling aluminum alloy 7075-T6 at high cutting speed under MQL condition. An eight-run experiment was designed according to full factorial design based upon two levels of cutting speed $(500 \mathrm{~m} / \mathrm{min}, 600 \mathrm{~m} / \mathrm{min})$, feed rate $(0.12$ $\mathrm{mm} / \mathrm{tooth}, 0.15 \mathrm{~mm} / \mathrm{tooth})$, and axial depth of cut (1.40 mm, 1.70 $\mathrm{mm}$ ) and then analyzed employed ANOVA to determine the significant machining parameters. The cutting tool life and machined surface roughness were assigned by the rejection criterion of tool flank wear in the milling operation. The optical microscope and portable surface roughness tester were applied to analyze tool wear and average surface roughness value. Cutting speed and feed rate were significantly contributing to the tool life and surface roughness. The longest tool lifespan of 20.14 minutes and lowest surface roughness value of $0.569 \mu \mathrm{m}$ were obtained at a speed of 500 and $600 \mathrm{~m} / \mathrm{min}$, respectively, with a low combination of the rest of parameter which are $0.12 \mathrm{~mm} /$ tooth and $1.40 \mathrm{~mm}$.
\end{abstract}

Keywords: Minimum Quantity Lubrication, Machining Parameters, Aluminum Alloy 7075-T6, Tool Life, Surface Roughness.

\section{INTRODUCTION}

Over the year the machining industries has become more and more stringent on the usage of machining fluid or lubrication due to the rise of concern on how it effects their worker and especially the general environment as a whole while abiding to the international standard 14001 which is to

Revised Manuscript Received on December 30, 2019.

* Correspondence Author

M.Z.A Yazid, Manufacturing Section, Universiti Kuala LumpurMalaysia Italy Design Institute, Kuala Lumpur, Malaysia. Email: mzaiday@unikl.edu.my

Azreen Zainol, Manufacturing Section, Universiti Kuala LumpurMalaysia Italy Design Institute, Kuala Lumpur, Malaysia. Email: azreen_zainol@yahoo.com.my

A.M. Mustapaha, Manufacturing Section, Universiti Kuala Lumpur-Malaysia Italy Design Institute, Kuala Lumpur, Malaysia. Email: abdulmuizmustapaha@gmail.com

(C) The Authors. Published by Blue Eyes Intelligence Engineering and Sciences Publication (BEIESP). This is an open access article under the CC BY-NC-ND license (http://creativecommons.org/licenses/by-nc-nd/4.0/) protect the environment from industrial waste [1]. In the machining process, the uses of the coolant are to take away the heat generated by the material removal process and the heat arise at the cutting edge as it will affect the final work piece quality and many researchers have shown that the cooling method used while machining the work piece will have an impact on determining the quality of the surface roughness of the finished product [2]. Cutting fluid have been used in many machining process to cool down the tool and the cutting zone of the machined work piece. However, it is expensive and bring negative impact on the environment [3]. Hannu et al. [4] found out that respiratory and skin symptoms was reported as common diseases occurred in metal working machinist who kept regular contact with metal cutting fluid One of the solution for this problem is using an alternative way to cool down the workpiece during machining process. Joshua et al [5] suggested the uses of minimum quantity lubrication (MQL), a method where a very minimum amount of fluid in range of 5 to $100 \mathrm{~mL} / \mathrm{h}$ is sprayed to cutting edge in the mist form during the machining process and has proven to benefit environment. This however introduce a new parameter in the machining process and different machining parameter will produce different results, an analysis of the surface topography of aluminum 7075 showed that the surface roughness was sensitive to changes in cutting parameters [6]. This interaction of cutting speed, feed rate, depth of cut and lubrication method have to be researched properly first before any machining process is to be taken on in order to obtain the optimum result such as good surface roughness, longer tool life, chip breakage, reducing cutting temperature, reducing cutting force and various others outcomes [7]. This paper presents the impact of involved machining parameters in milling towards the tool life and surface roughness of aluminum alloy 7075-T6 at high speed cutting under MQL condition.

\section{METHODOLOGY}

Aluminum alloy 7075-T6 along with a length of $300 \mathrm{~mm}$, a width of $150 \mathrm{~mm}$ and a thickness of $40 \mathrm{~mm}$ was milled DECKEL MAHO DMU 50 eVolution CNC five axes milling machine using uncoated carbide insert. Machine tool equipped with functional capabilities of spindle speed and feed, which are $16000 \mathrm{rpm}$ and $20000 \mathrm{~mm} / \mathrm{min}$, respectively. The composition of work piece material was Al of $90.3 \%$, Zn of $5.6 \%, \mathrm{Mg}$ of $2.5 \%$, and $\mathrm{Cu}$ of $1.6 \%$ as provided by the manufacturer. 


\section{Effect of Machining Parameters in Milling Aluminum Alloy 7075-T6 under MQL Condition}

A thickness of the work piece surface almost 1 to $2 \mathrm{~mm}$ was skimmed off in order to eliminate any surface flaws that can influence the machining result. The controlled machining parameters includes cutting speed (vc) of 500 and $600 \mathrm{~m} / \mathrm{min}$, feed rate (fz) of 0.12 and $0.15 \mathrm{~mm} /$ tooth, and axial depth of cut (ap) of 1.40

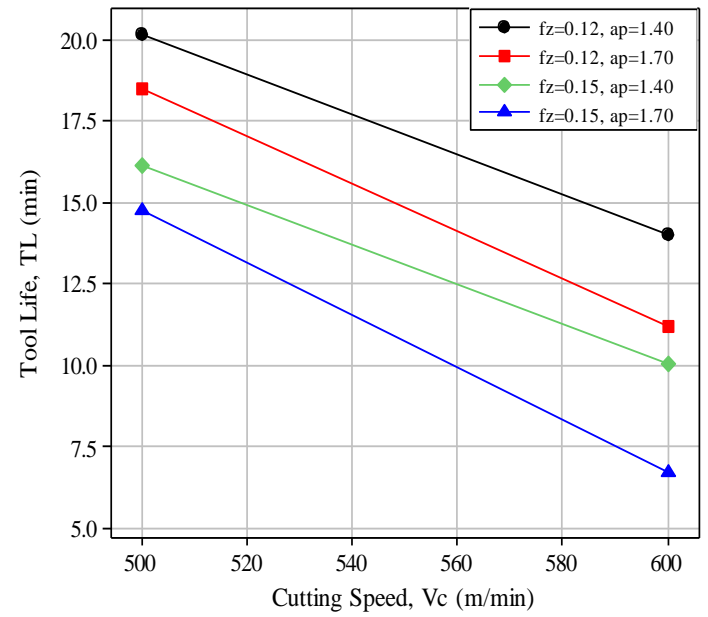

(a)

\section{RESULTS AND DISCUSSION}

Table 1 shows the results of the cutting tool life and machined surface roughness with the full factorial design. The results obtained from eight experiment runs.

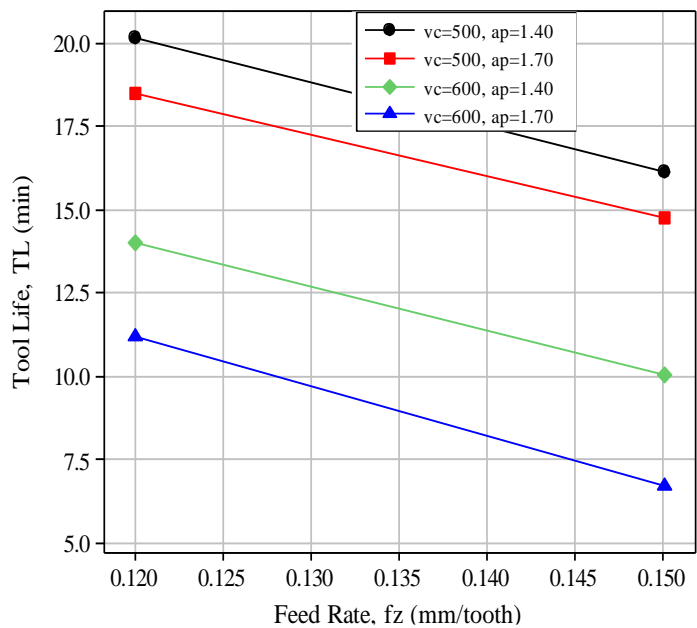

(b)

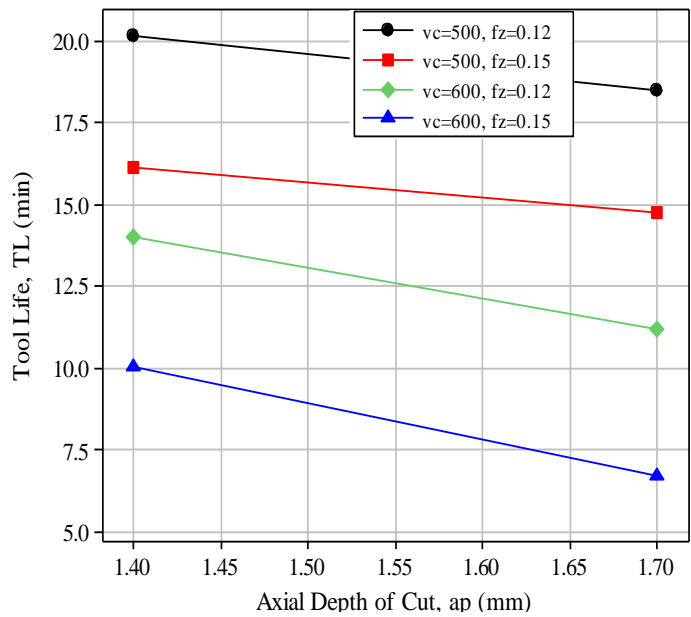

(c)

Fig. 1. Effect of machining parameter on tool life (a) cutting speed (b) feed rate (c) axial depth of cut

and $1.70 \mathrm{~mm}$ while the radial depth of cut (ae) restricted to 14 $\mathrm{mm}$.

The tool life criterion was evaluated after achieving tool flank wear (vb) of $0.30 \mathrm{~mm}$ in accordance with ISO 8688-2-1989 [8]. Flank wear was examined and measured at every pass interval employed an optical microscope in which manufactured by Olympus BX53M. Furthermore, the measurements of surface roughness $(\mathrm{Ra})$ were determined on the machined surface using Mitutoyo Surftest SJ-210 portable surface roughness tester and $0.80 \mathrm{~mm}$ was set as cutoff distance. The $\mathrm{Ra}$ values were measured at three different locations in the perpendicular direction to feed and subsequently, the Ra average was computed. A full factorial design was applied for the ease of designing the experiments carried out wherein a total of eight runs was developed that ensue from a merger of three controlled factors and two levels. Analysis of variance (ANOVA) was then employed to define the machining parameters most influence tool life and surface roughness.

Table 1: Result of tool life and surface roughness

\begin{tabular}{|c|c|c|c|c|c|}
\hline No & $\begin{array}{c}\text { vc, } \\
(\mathrm{m} / \mathrm{min})\end{array}$ & $\begin{array}{c}\text { fz, } \\
(\mathrm{mm} / \text { tooth })\end{array}$ & $\begin{array}{c}\text { ap, } \\
(\mathrm{mm})\end{array}$ & $\begin{array}{c}\text { TL, } \\
(\mathrm{min})\end{array}$ & Ra, $(\mu \mathrm{m})$ \\
\hline 1 & 500 & 0.12 & 1.40 & 20.14 & 0.691 \\
\hline 2 & 500 & 0.12 & 1.70 & 18.46 & 0.720 \\
\hline 3 & 500 & 0.15 & 1.40 & 16.11 & 0.752 \\
\hline 4 & 500 & 0.15 & 1.70 & 14.77 & 0.803 \\
\hline 5 & 600 & 0.12 & 1.40 & 13.99 & 0.569 \\
\hline 6 & 600 & 0.12 & 1.70 & 11.19 & 0.605 \\
\hline 7 & 600 & 0.15 & 1.40 & 10.07 & 0.635 \\
\hline 8 & 600 & 0.15 & 1.70 & 6.71 & 0.680 \\
\hline
\end{tabular}

Tool life is denoted as TL where defined as the total cutting time when the tool has become worn. It was normally occurring due to the temperature produced in the cutting edge. From Table 1, the experimental results of the tool life show that the lifespan between 6.71 and 20.14 minutes was taken.

Published By: 


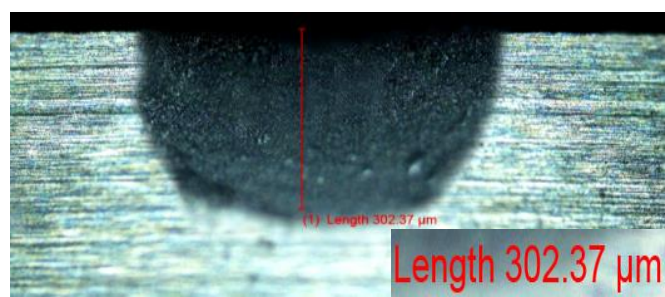

(a)

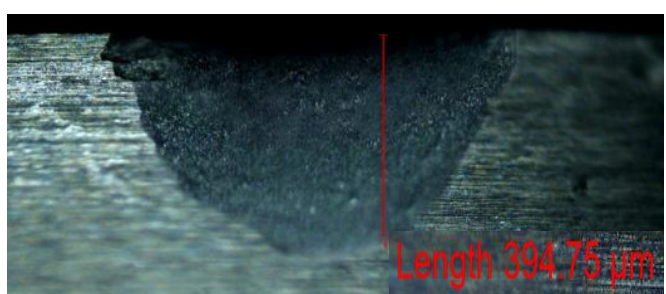

(b)

Fig. 2. Tool flank wear at (a) longest tool life (b) shortest tool life

Maximum tool life of 20.14 minutes was attained at cutting speed of $500 \mathrm{~m} / \mathrm{min}$, the feed rate of $0.12 \mathrm{~mm} /$ tooth, and axial depth of cut of $1.40 \mathrm{~mm}$ after milling with the uncoated carbide. The shortest tool life of 6.71 minutes was obtained at an elevated merger of cutting speed, feed rate, and axial depth of cut, which are $600 \mathrm{~m} / \mathrm{min}, 0.15 \mathrm{~mm} /$ tooth, and $1.70 \mathrm{~mm}$, respectively.

Figure 1 illustrates the influence of machining parameters on tool life. Prolonged tool lifespan was obtained by a decrease in cutting speed and feed rate along with the axial depth of cut as depicted in Figure 1 (a). The shortest tool life was obtained by a heightened in the value in cutting speed, feed rate, and axial depth of cut. Similar results were revealed by Khorasani et al. [9] who study the correlation of 7075-T6, mainly cutting speed, feed rate, and depth of cut on tool life employ Artificial Neural Networks (ANN). However, they found that the longest tool life was taken at the rate. It seems that the contradicting machining parameters were suspected due to a small ability of machine tool in a tendency to achieve a longer tool life.

In addition, Figure 1 (b) depicts the result of the feed rate effect on the tool life shows it decreases as the feed rate increases from 0.12 to $0.15 \mathrm{~mm} /$ tooth. The shortest tool life of 6.71 minutes occurs at a feed rate of $0.15 \mathrm{~mm} /$ tooth at a speed of $600 \mathrm{~m} / \mathrm{min}$. The longest tool lifespan of 20.14 minutes occurred at a feed rate of $0.12 \mathrm{~mm} /$ tooth at a speed of $500 \mathrm{~m} / \mathrm{min}$. It revealed that a low feed rate offers a longer tool lifespan. Apart from that, Figure 1 (c) exhibits the influence of axial depth of cut on tool life at each cutting speed and feed rate. It is evident that the tool life decreases when the axial depth of cut was increased from 1.40 to $1.70 \mathrm{~mm}$. The longest and shortest lifespan, which is 20.14 and 6.71 minutes occurred in the axial depth of cut of 1.40 and $1.70 \mathrm{~mm}$ at a speed of 500 and $600 \mathrm{~m} / \mathrm{min}$, respectively. It reveals that longer tool life can be achieved with a low axial depth of cut.

Figure 2 (a) and (b) exhibits the tool flank wear on the uncoated carbide inserts under the near-dry machining at low combination of machining parameters and vice versa, respectively. It is noticed that a good wear pattern has appeared in the longest tool life of 20.14 minutes compared to shorter tool life caused by the capability of low values of machining parameter in decelerating the cutting temperature indirectly prevent the thermal shock on the cutting tool edge.

Table 2 presents the ANOVA results pertaining to the cutting tool life under MQL. It shows clearly that the cutting speed was most influence the tool life followed by feed rate due to the P-values are less than 0.05 at $95 \%$ confidence level. P-values of 0.021 and 0.036 were representing both machining parameters in the end milling of aluminum moderate value in cutting speed and the lowest value of feed

significant factors. On the other hand, the other factors and interactions as stated in Table 2 are a negligible influence on tool life due to the fact the P-value is greater than 0.05 .

Table 2. ANOVA for tool life

\begin{tabular}{|c|c|c|c|c|}
\hline Factor & DF & SS & $\boldsymbol{F}$ & $\boldsymbol{P}$ \\
\hline $\mathrm{vc}$ & 1 & 94.669 & 935.00 & 0.021 \\
\hline $\mathrm{fz}$ & 1 & 32.482 & 320.81 & 0.036 \\
\hline $\mathrm{ap}$ & 1 & 10.534 & 104.04 & 0.062 \\
\hline $\mathrm{vc}^{*} \mathrm{fz}$ & 1 & 0.058 & 0.57 & 0.588 \\
\hline $\mathrm{vc}^{*} \mathrm{ap}$ & 1 & 1.232 & 12.17 & 0.178 \\
\hline $\mathrm{fz} * \mathrm{ap}$ & 1 & 0.006 & 0.06 & 0.847 \\
\hline Error & 1 & 0.101 & & \\
\hline Total & 7 & 139.082 & & \\
\hline
\end{tabular}

The surface roughness $(\mathrm{Ra})$ on the machined surface was influenced by the machining parameters and condition. In general, the lower value of Ra provides a promising effect on the surface of the machine. Figure 3 shows the results for surface roughness at varying machining parameter using uncoated carbide inserts. From Table 2, the results of the surface roughness show that the $\mathrm{Ra}$ values between about 0.569 and $0.803 \mu \mathrm{m}$ was recorded. Lowest Ra value of 0.569 $\mu \mathrm{m}$ was obtained at cutting speed of $600 \mathrm{~m} / \mathrm{min}$, the feed rate of $0.12 \mathrm{~mm} /$ tooth, and axial depth of cut of $1.40 \mathrm{~mm}$ after milled with the uncoated carbide. Maximum Ra of $0.803 \mu \mathrm{m}$ was obtained at cutting speed, feed rate, and axial depth of cut, which are $500 \mathrm{~m} / \mathrm{min}, 0.15 \mathrm{~mm} /$ tooth and $1.70 \mathrm{~mm}$, respectively.

Figure 3 illustrates the influence of machining parameters on surface roughness. Maximum Ra was obtained by an increase in the values of cutting speed, feed rate and the axial depth of cut as depicted in Figure 3 (a). The minimum Ra was obtained by a decrease in cutting speed and high combination feed rate of $0.15 \mathrm{~mm} /$ tooth and axial depth of cut of $1.70 \mathrm{~mm}$. Obviously, this experiment affirms the fact that a high cutting speed with the low combination of feed rate and axial depth of cut has the potential to promote a favourable solution in the machining process [10]. Anwar et al. [11] have also reported similar results that the minimal $\mathrm{Ra}$ value was achieved at high cutting speed and low feed, which are 5000 $\mathrm{rpm}$ and $900 \mathrm{~mm} / \mathrm{min}$, respectively. Furthermore, Figure 3 (b) shows the result of the feed rate influence on the surface roughness. It increases with the feed rate from 0.12 to 0.15 $\mathrm{mm} /$ tooth. The lowest Ra value of $0.569 \mu \mathrm{m}$ occurs at a feed rate of $0.12 \mathrm{~mm} /$ tooth at a speed of $600 \mathrm{~m} / \mathrm{min}$. Whilst, the highest Ra value of $0.803 \mu \mathrm{m}$ occurred at a feed rate of 0.15 $\mathrm{mm} /$ tooth at a speed of $500 \mathrm{~m} / \mathrm{min}$. It revealed that a low feed rate offers a better 


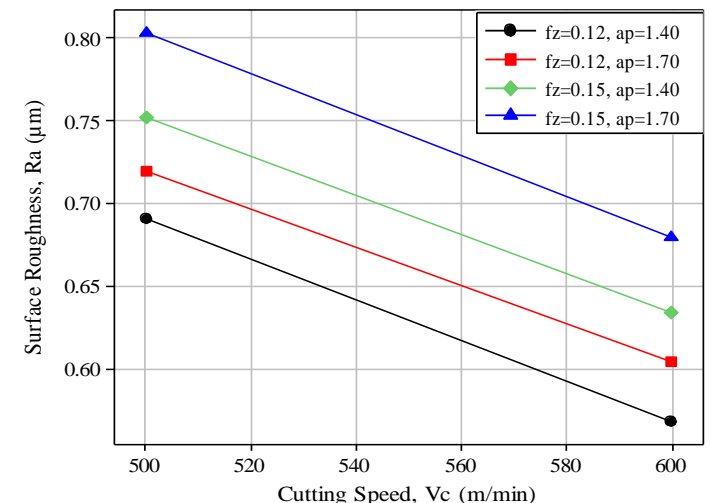

(a)

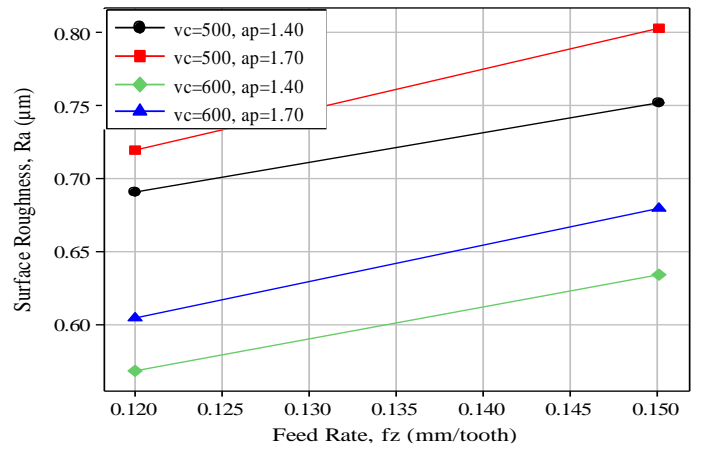

(b)

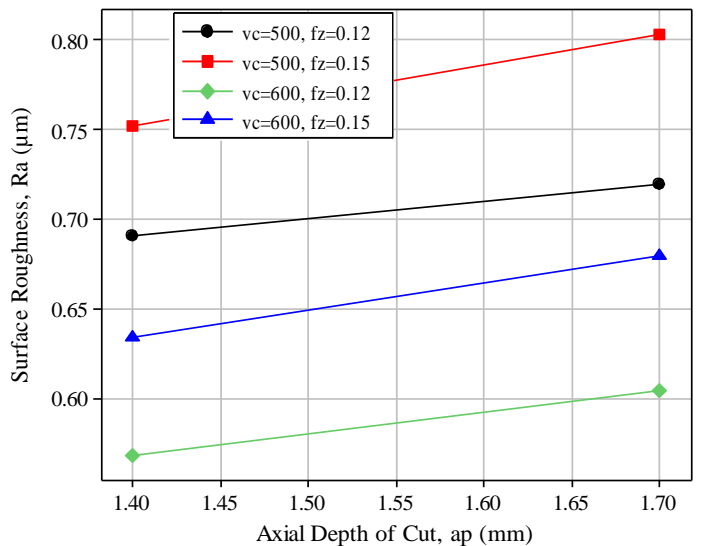

(c)

Fig. 3. Effect of machining parameter on tool life (a) cutting speed (b) feed rate (c) axial depth of cut

surface roughness. Besides that, Figure 3 (c) exhibits the influence of axial depth of cut on surface roughness at each cutting speed and feed rate. It is clear that the surface roughness increases when the axial depth of cut was increased from 1.40 to $1.70 \mathrm{~mm}$. The low and high Ra value, namely 0.569 and $0.803 \mu \mathrm{m}$ occurred in the axial depth of cut of 1.40 and $1.70 \mathrm{~mm}$ at a speed of 600 and $500 \mathrm{~m} / \mathrm{min}$, respectively. It seems that the lowest $\mathrm{Ra}$ value can be achieved with a low axial depth of cut.

Figure 4 illustrates a comparison of the effects of cutting speed of 500 and $600 \mathrm{~m} / \mathrm{min}$ on the surface roughness at a feed rate of $0.12 \mathrm{~mm} /$ tooth and axial depth of cut of $1.40 \mathrm{~mm}$. It is evident that the surface roughness at initial cutting for the speed of $600 \mathrm{~m} / \mathrm{min}$ was lower than $500 \mathrm{~m} / \mathrm{min}$. The surface roughness values at a speed of $600 \mathrm{~m} / \mathrm{min}$ were constantly lower than $500 \mathrm{~m} / \mathrm{min}$ at every cutting time. However, the Ra value was found lower substantially in a minute of 8.42 throughout near-dry milling at a speed of $600 \mathrm{~m} / \mathrm{min}$. This occurs possibly due to a smoother cutting edge tends to the better roughness. Surface roughness at a speed of $500 \mathrm{~m} / \mathrm{min}$ was found to be higher at the final of the tool lifespan from the initial cutting.

Table 3 exhibit the ANOVA results on the machined surface roughness under MQL. It is evident that the cutting speed has the most significant effects followed by feed rate on the surface roughness due to a smaller P-values of 0.05 at 95\% confidence level. P-values for both significant factors were 0.017 and 0.029 . Additionally, the other factors and interactions are a negligible effect because of the fact the $\mathrm{P}$-value is greater than 0.05 .
From Figure 1 and 3, the excellent results for tool life and surface roughness was reached at 600 and $500 \mathrm{~m} / \mathrm{min}$, respectively, with the feed rate of $0.12 \mathrm{~mm} /$ tooth and axial depth of cut of $1.40 \mathrm{~mm}$. It occurs consequently the occurrence of low friction in the tool-work contact region in achieving the longest tool life and high shear pressure between the work piece and chips to obtain better surface roughness.

\section{CONCLUSION}

The paper provides an experimental work towards the tool life and surface roughness of aluminum alloy 7075-T6 involving the key milling parameters under MQL condition using the uncoated carbide inserts. Raise and diminish in cutting speed and low of feed rate and axial depth of cut resulted in a promising performance of tool life and surface roughness, respectively. The cutting at speeds of 500 and 600 $\mathrm{m} / \mathrm{min}$ at the feed rate of $0.12 \mathrm{~mm} /$ tooth and axial depth of cut of 1.40 has offered to extend the tool life and minimize surface roughness value, respectively. From ANOVA results, the cutting speed was found to be the most significant factor, followed by the feed rate that affects cutting tool life and machined surface roughness. The cutting temperature has an influence in achieving the prolonged tool lifespan that controls by a low combination of machining parameters to prevent the thermal shock on the tool edge.

Published By:

Blue Eyes Intelligence Engineering \& Sciences Publication

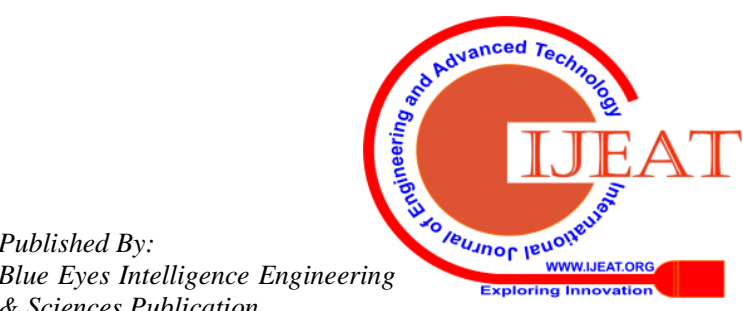




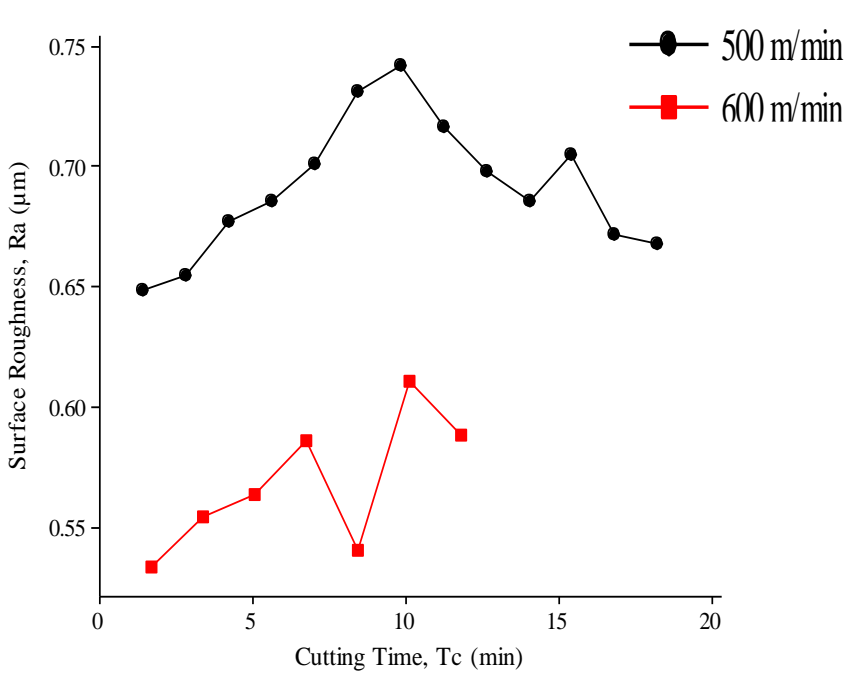

Fig. 4. Comparison of surface roughness trend at different cutting speed with feed rate of $0.12 \mathrm{~mm} /$ tooth and axial depth of cut of $1.40 \mathrm{~mm}$

Table 3. ANOVA for surface roughness

\begin{tabular}{|c|c|c|c|c|}
\hline Factor & DF & SS & $\boldsymbol{F}$ & $\boldsymbol{P}$ \\
\hline $\mathrm{vc}$ & 1 & 0.0284411 & 1346.33 & 0.017 \\
\hline $\mathrm{fz}$ & 1 & 0.0101531 & 480.62 & 0.029 \\
\hline $\mathrm{ap}$ & 1 & 0.0032401 & 153.38 & 0.051 \\
\hline $\mathrm{vc} * \mathrm{fz}$ & 1 & 0.0000011 & 0.05 & 0.856 \\
\hline vc*ap & 1 & 0.0000001 & 0.01 & 0.951 \\
\hline fz*ap & 1 & 0.0001201 & 5.69 & 0.253 \\
\hline Error & 1 & 0.0000211 & & \\
\hline Total & 7 & 0.0419769 & & \\
\hline
\end{tabular}

\section{ACKNOWLEDGMENT}

The authors sincerely to extend the highest gratitude to Universiti Kuala Lumpur Short-Term Research Grant (STR 15051) for the financial support to stimulate the effectiveness of research work.

\section{REFERENCES}

1 V. S. Sharma, G. Singh, and K. Sorby, "A review on minimum quantity lubrication for machining processes," Material and Manufacturing Processes, vol. 30, no. 8, pp. 935-953, 2015.

2 Y. Shokoohi, E. Khosrojerdi, and B. H. Rassolian Shiadhi, "Machining and ecological effects of a new developed cutting fluid in combination with different cooling techniques on turning operation," Journal of Cleaner Production, vol. 94, pp. 330-339, 2015.

3 J. Kouam, V. Songmene, M. Balazinski, and P. Hendrick, "Effects of minimum quantity lubricating (MQL) conditions on machining of 7075-T6 aluminum alloy," International Journal of Advanced Manufacturing Technology, vol. 79, no. 8, pp. 1325-1334, 2015.

4 T. Hannu, K. Suuronen, K. Aalto-Korte, K. Alanko, R. Luukkonen, M. Järvelä, R. Jolanki, and S. M. Jaakkola, "Occupational respiratory and skin diseases among finnish machinists: findings of a large clinical study," International Archives of Occupational and Environmental Health, vol. 86, no. 2, pp. 189-197, 2013.

5 O. S. Joshua, M. O. David, and I. O. Sikiru, "Experimental Investigation of Cutting Parameters on Surface Roughness Prediction during End Milling of Aluminium 6061 under MQL ( Minimum Quantity Lubrication )," Journal of Mechanical Engineering and Automation, vol. 5, no. 1, pp. 1-13, 2015.

6 W. Jomaa, V. Songmene, and P. Bocher, "Surface finish and residual stresses induced by orthogonal dry machining of AA7075-T651," Materials, vol. 7, no. 3, pp. 1603-1624, 2014.

7 A. K. Sharma, A. K. Tiwari, and A. R. Dixit, "Effects of Minimum Quantity Lubrication (MQL) in machining processes using conventional and nanofluid based cutting fluids: A comprehensive review," Journal of Cleaner Production, vol. 127, pp. 1-18, 2016.

8 M. S. Kasim, C. H. Che Haron, J. A. Ghani, M. A. Sulaiman, and M. Z. A. Yazid, "Wear mechanism and notch wear location prediction model in ball nose end milling of Inconel 718," Wear, vol. 302, no. 2, pp. 1171-1179, 2013.

9 A. M. Khorasani, M. Reza Soleymani Yazdi, and M. S. Safizadeh, “Tool life prediction in face milling machining of 7075 aluminum by using artificial neural networks (ANN) and taguchi design of experiment (DOE)," International Journal of Engineering and Technology, vol. 3, no. 1, pp. 30-35, 2011.

10 S. Rawangwong, J. Chatthong, W. Boonchouytan, and R. Burapa, “An investigation of optimum cutting conditions in face milling aluminum 7075-T6 using design of experiment," Energy Procedia, vol. 4, pp. 125-135, 2013.

11 R. Anwar, M. Jahanzaib, G. Asghar, A. Wasim, and S. Hussain, "Optimization of surface roughness for aluminum alloy 7075-T6 in milling process," Technical Journal, University of Engineering and Technology Taxila, Pakistan, vol. 20, no. 2, pp. 153-159, 2015.

\section{AUTHORS PROFILE}

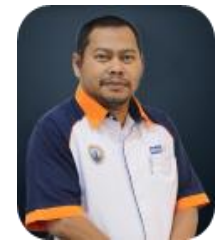

M.Z.A. Yazid is Associate Professor in Manufacturing Section at Universiti Kuala Lumpur-Malaysia Italy Design Institute, Kuala Lumpur, Malaysia. He receives his Master of Science in Engineering Business Management and Ph.D. in Mechanical and Materials Engineering, from University of Warwick, United Kingdom and Universiti Kebangsaan Malaysia, Selangor, Malaysia, respectively. His research areas include Mechanical Properties, Corrosion, Machining, and Materials. A recent publication is "Environmentally friendly approaches assisted machining of aluminum alloy 7075-T6 for automotive applications: a review".

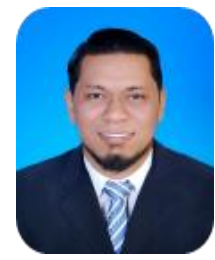

Azreen Zainol is currently pursuing Master of Engineering Technology (Manufacturing) in Universiti Kuala Lumpur-Malaysia Italy Design Institute, Kuala Lumpur, Malaysia. He holds a Bachelor of Engineering Technology in Manufacturing Systems in 2014 from Universiti Kuala Lumpur-Institute of Product Design and Manufacturing after completing Diploma in Manufacturing Technology from Kolej Kemahiran Tinggi MARA, Penang, Malaysia. His research mainly focuses on Metal Cutting, Cutting Tools, and Fluid Techniques. He is performing research to develop sustainable machining processes, which are environmentally friendly and harmless to the machining operators.

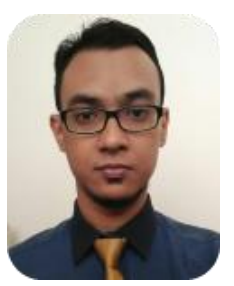

A.M. Mustapaha is currently a postgraduate student of Master of Engineering Technology (Manufacturing) at Universiti Kuala Lumpur-Malaysia Italy Design Institute, Kuala Lumpur, Malaysia. He receives a Bachelor of Engineering Technology in Manufacturing Systems and Higher National Diploma in Mechanical Engineering from respective Universiti Kuala Lumpur-Institute of Product Design and Manufacturing, Kuala Lumpur and Linton University College, Negeri Sembilan, Malaysia. He is a Registered Engineering Technologist in Malaysia. His current research is focusing on Milling Operation, Surface Integrity, and Metalworking Fluids. He is performing research to provide superior machining performance with the aid of proper selection eco-friendly cutting fluids. 